\title{
Classifying Motivations in Social Product Development Networks: A Discriminant Analysis of Actor Profiles
}

\author{
Kaveh Abhari \\ San Diego State University \\ kabhari@sdsu.edu
}

\author{
Elizabeth J. Davidson \\ University of Hawai'i at Mānoa \\ edavidso@hawaii.edu
}

\author{
Bo Xiao \\ University of Hawai'i at Mānoa \\ boxiao@hawaii.edu
}

\begin{abstract}
This study develops a classification model to predict social actors' co-innovation behavior in social product development (SPD) networks based on motivational differences. The study first identifies motivations for actors to continuously participate in co-innovation activities. Then, three discriminant functions are developed and cross-validated to classify actor groups, based on their level of willingness to participate in three types of behaviors: ideation, collaboration, and socialization. The results indicate that financial gains, entrepreneurship, and learning are significant predictors of ideation behaviors. Enjoyment and learning are strong indicators of collaboration, whereas networking, enjoyment, and altruism are most strongly related to socialization behaviors. These findings highlight three classes of SPD actors (Ideators, Collaborators, and Networkers) based on motivational differences. These classes provide a theoretically parsimonious model to predict the co-innovation behaviors in SPD and highlight the importance of platform design to appeal to different classes of potential contributors.
\end{abstract}

\section{Introduction}

Information and Communication Technologies (ICT) have opened innovation process by enabling individuals to engage in all phases of new product development (NPD). Recent developments involve the application of social technologies in new product development [41]. Specifically, Social Product Development (SPD) extends opportunities for collaboration across the spectrum of innovation activities to individuals who are socially engaged in the development of new products [65]. SPD is a socially-enabled, user-driven, and product-centric approach to NPD enabled by social technologies and social mechanisms [2]. The SPD lifecycle consists of a series of inter-related processes, including engaging social actors who are organizationally independent, socially connected, and personally motivated individuals. These external co-innovators, referred to as 'actors' in this paper, are the main capitals for all co-innovation projects.

The SPD model-building on earlier models for open innovation and sharing some characteristics with co-innovation business models - presents a distinctive value proposition for innovation sponsors by placing actors at the heart of the NPD process and governance $[19,36,54]$. The SPD model engages actors with different motivations in a wide range of activities afforded by social technology, thereby redefining actor co-innovation behavior [28, 47].

A limited understanding of actor behavior in SPD and motivations driving their behavior is responsible for limiting the co-innovation coordinators' ability to develop and sustain appropriate reward systems to govern the embryonic stage of NPD. SPD networks depend on a high level of actor agency and involvement in the innovation process, which in turn requires appropriate reward mechanisms to satisfy social actors' expectations. Actors' motivations to participate in the co-innovation could result in dramatically different contribution patterns [15]. Past research on actors' co-innovation behavior has focused primarily on open source and virtual customer communities [e.g., 21, 36, 37, 46]. This research provides insights relevant to SPD, but it does not fully explain actor behavior in these new types of platforms.

Understanding why actors engage in SPD is a critical first step to investigate the viability of this coinnovation model and to inform the design of business model rules, structures, and social technology platforms that enhance innovation outcomes [8, 29, 59]. Research that examines motivations allows for a clearer understanding of the classes of actors who participate in SPD, and therefore how SPD platforms might be developed to satisfy a range of contributors [22]. To this end, this paper investigates whether actors' motivations influence their intention to participate in a specific co-innovation activity. We first consider the motivational differences underlying three types of co-innovation behaviors: ideation, collaboration and socialization [2, 24]. We use a discriminant function analysis to build a classification 
model for motivation constructs that discriminate between high and low participation in these different SPD behaviors. We next consider which clusters of motivations best predict ideation, collaboration, and socialization behaviors in SPD networks. We identify three classes of participants from this: Ideators, Collaborators, and Networkers. We then consider the theoretical and practical implications of results for developing reward systems to increase and enhance participation in SPD platforms.

\section{Theoretical Background}

Actor motivation explain why individuals join a network and contribute to a co-innovation activity. Various types of motivations are evident in different open innovation platforms, because motivations may vary according to the specific co-innovation model [22]. Thus, the unique characteristics of SPD models are relevant to actor motivation.

\subsection{SPD Platform Business Models}

Virtual customer networks are traditionally userdriven and product-centric online environments where customers can share their experience, feedback, or knowledge contributing to the new product or service development [31, 44]. The implementation of such online environments involves taking a participatory approach to R\&D [40]. The popularity of emerging social technology has helped businesses take this participatory approach to the next level beyond the customer base [42]. For example, SPD models heavily rely on social technologies and social mechanisms to facilitate new product development [52].

While the SPD model bears some resemblance to virtual customer networks sponsored by a firm to engage its own customers in innovation activities [65], the owner of an SPD platform acts primarily as an innovation intermediary rather than as a corporation seeking to improve its own product portfolio. For instance, in SPD networks such as Quirky and Edison Nation, members submit new ideas and suggest how to improve others' ideas. Using member input, the platform owner then selects the products to bring to market and shares profits with contributors.

SPD also differs from co-innovation networks such as open source communities, crowdsourcing firms, or innovation brokers in terms of business models and the variety and prominence of activities open to community members. The SPD network approach values co-creation by fully developing and utilizing external actors' capabilities, which leads to diminished boundaries between internal and external actors [6]. Thus, SPD participants have a higher level of direct participation in NPD than in other co- innovation business models. SPD networks also have different approaches to value co-creation due to the variety of tasks and activities performed by actors [22]. Such high levels of participation and ownership in the co-innovation process may result in attracting actors with different goals, interests, and backgrounds, and therefore a different mix of actor motivations.

\subsection{SPD Motivations}

Engaging actors is a fundamental challenge for coinnovation communities like SPD networks [4, 21], because co-innovation tends to simultaneously involve more than one type of motivation. Drawing on selfdetermination theory [8], prior research has identified intrinsic and extrinsic motivations in open innovation communities and suggests that intrinsic and extrinsic motivations should be considered together in analyzing actor co-innovation behaviors [10, 22].

Extrinsic motivation is mainly associated with extrinsic rewards (e.g., financial gain) that arise from sources outside of the actor [50]. Extrinsic motivation is not limited to financial compensation but can also include the prospect of status and image [57]. For example, research shows that some actors participate in the virtual co-innovation communities for professional recognition and reputation [14, 38].

Intrinsic motivation is associated with the needs and desires within the actor [57]. Prior research shows that individuals engage in co-creation activities such as submitting new product ideas, finding solutions to problems in collaboration with like-minded people, and commercializing new products for their own sake because they perceive such activities to be enjoyable $[4,7]$. Altruism is another key dimension of intrinsic motivation. Actors may participate in an SPD because of their desire to support others in problem-solving activities [22, 48] or because they believe in the mission of the network or project [33]. Altruism based on belief in the community's goals helps explain actors' contribution to SPDs like the open source software community [37].

Research also shows that some motivations are neither purely intrinsic nor extrinsic. According to Ryan and Deci [25], external motivations can be internalized when individuals transform external incentives (i.e., external regulation) into their own motives (i.e., self-regulation) through the processes of introjection (i.e., enhancement of self-esteem and feelings of worth), identification (i.e., acceptance as personally important or relevant), or integration (i.e., endorsement of values or beliefs) [25]. Prior research has identified learning and development, self-efficacy, entrepreneurial mindset, and social motivations as four important dimensions of internalized extrinsic motivations driving actors' participation [4, 15, 24]. 
Table 1 summarizes eight major categories of actor motivations identified in prior co-innovation literature, which serves as the foundation for this investigation of SPD actor motivations. Research suggests that these motivations all play roles in attracting and engaging participants in co-innovation activities. However, findings are inconsistent regarding the relative influences of different actor motivations on different co-innovation behaviors [22, 36]. Accordingly, in this study, we focus on the eight motivation constructs that are frequently observed in open innovation communities but have not been tested in SPD context, to our knowledge. The motivation constructs are Financial Gain, Recognition, Learning, Self-efficacy, Entrepreneurship, Networking, Enjoyment and Altruism.

Table 1. Prior research on co-innovation motivation

\begin{tabular}{ll}
\hline MOTIVATION & \multicolumn{1}{c}{ PRIOR RESEARCH } \\
\hline Financial Gain & $\begin{array}{l}\text { Compensation [22]; Desire for monetary } \\
\text { rewards [20]; Reward or free product [7] }\end{array}$ \\
\hline \multirow{2}{*}{ Recognition } & $\begin{array}{l}\text { Recognition [11]; Reputation [7, 50, 62]; Peer } \\
\text { recognition [3, 62] and Firm recognition [34, } \\
\text { 35] }\end{array}$ \\
\hline \multirow{2}{*}{ Learning } & $\begin{array}{l}\text { Self-development [50]; Learning [7, 11]; } \\
\text { Information seeking [22, 55]; Skills } \\
\text { development [22, 63]; Curiosity [22] }\end{array}$ \\
\hline Self-efficacy & $\begin{array}{l}\text { Self-efficacy [22]; Sense of influencing [3]; } \\
\text { Psychological gain [7] }\end{array}$ \\
\hline \multirow{2}{*}{ Entrepreneurship } & $\begin{array}{l}\text { Entrepreneurial mindset [6, 7]); Product } \\
\text { improvement [11]; New viewpoints and } \\
\text { synergy [3]; Interesting objectives [55]; }\end{array}$ \\
\hline Networking & $\begin{array}{l}\text { Friendships [55] Social recognition [22]; } \\
\text { Social capital [3, 7]; Social networking [49]; }\end{array}$ \\
\hline \multirow{2}{*}{ Enjoyment } & Entertainment and fun [3, 6, 7, 11] \\
\hline Enjoyment [20, 30, 39, 50];
\end{tabular}

\subsection{Actor Behavior}

This study focuses on behavioral intention, and continuous intention in particular, as a proxy for SPD behavior. An actor's continuous intention to contribute to SPD is more important than the initial decision to join an SPD network since these networks are heavily influenced by users' post-adoption behavior [65]. Drawing from Gloor's three-dimension actor participation structure [24], we conceptualize intention to contribute as an actor's continuous intention to engage in the three interrelated activities of ideation, collaboration, and socialization [12, 17, $23,36,54]$. Co-innovation platforms typically provide a variety of social technology features to enable these behavior [2, 24]. These three high-level behaviors are applicable to a variety of co-innovation settings [1].
In socially enabled co-innovation networks, ideation is often referred to new product idea proposition, which is an initial and critical component of co-innovation processes [56]. The ideation process enables actors to perform tasks such as submitting new ideas or solutions in the form of a new product, product feature, or product category [60]. Collaboration is also essential to any socially enabled co-innovation system [45]. Collaboration involves interactions among internal and external actors on a specific project to address problems and find or improve solutions [54]. Collaboration relates to a range of interdependent activities, from enhancing other actors' ideas to participating in commercialization activities [43]. Because of the distributed nature of the co-innovation process, socialization between actors, such as networking and sharing knowledge, is an inherent aspect throughout co-innovation processes and activities [51]. Networking features facilitate co-innovation processes through establishing a socio-professional community enriching ideation and facilitating collaboration.

\section{$2.4 \quad$ Hypothesis}

In this study, we hypothesized that actor behavior changes with motivations. Successful ideation, collaboration, and socialization may individually and jointly provide opportunities for financial rewards and professional recognition. Actors who are motivated by enjoyment or altruistic goals may actively participate in co-innovation activities in SPD networks even without expecting external rewards. Hybrid rewards (internalized extrinsic) such as learning and networking can also be important drives for actor participation. While the literature suggests that motivation can predict participation in general, it does not specify particular kinds of participation. Hence, we hypothesized that the actors' motivations distinguish between different behaviors in terms of ideation, collaboration, and socialization. That means there are significant differences between the groups of actors participating in different co-innovation activities. Therefore, we aim at establishing and validating a classification model for explaining motivation-driven co-innovation behavior in SPD networks.

Identifying and classifying SPD motivations that drive actor behavior can be a significant contribution to SPD theory and practice by: (a) defining motivation-driven behavior; (b) informing the alignment of reward systems with actors' motivations; (c) providing a theoretical reference point for SPD platform design and governance; (d) explaining actor heterogeneity in terms of motivations; and (e) facilitating communication between researchers by a common language used in defining actor groups. 


\section{Research Design and Methods}

Data were collected via an online survey from a random sample of contributors to the Quirky.com SPD platform. Quirky is one of the first companies to implement a comprehensive model of SPD [54]. Quirky's business model is based on soliciting new product ideas for broad categories of consumer products and sharing a portion of the sales revenue with the community of innovators who contribute to product ideation as well as product selection, design, development, and promotion. Prospective inventors can submit their ideas for community evaluation as a part of the ideation process. The submitted ideas, if selected by the community, are collaboratively designed, developed, and commercialized by interested network members, including Quirky employees. The refined product ideas are then put to production by Quirky, and finally distributed via the Quirky website and its retail partners. Quirky compensates the individual contributors involved in the product's innovation process by paying up to $10 \%$ of any resulting revenue for each product. As of September 2017, more than 1.2 million members had collaboratively developed 150 consumer products and collectively received about $\$ 11$ million in royalties.

We employed discriminant function analysis to determine which motivation constructs discriminate between co-innovation actors' behaviors. Discriminant analysis is a recommended approach for maximally separating groups, determining the most parsimonious way to separate groups and discarding variables which are less related to group distinctions $[26,61]$. Discriminant analysis was used to determine which motivation factors were the best predictors of an actor's ideation, collaboration or socialization behavior, assessed in terms of continuous intention based on the surveyed data on eight different motivation constructs. In this process, the motivation constructs were discriminating variables and the continuous intention to ideate, collaborate, and socialize were the group variables. We followed the procedure proposed by Ho [32] using IBM SPSS 24 as described below.

After testing for Normality, Homogeneity (Eigenvalue), Equality of Group Mean and Withingroup Covariance (Box's M), the discriminant function (centroids) was calculated. Centroids are the mean discriminant score for each group. Wilks lambda was used to test for the significant difference between groups and between the groups on the individual motivation constructs. We used this statistic to identify which motivation factors contribute a significant amount of prediction to help separate the groups. We also used $\chi^{2}$ to obtain a significance level. The Canonical Discriminant Function Coefficients were then used to indicate the unstandardized scores concerning the motivation constructs.

The relative importance of motivation constructs in predicting actors' continuous intention was calculated using the standardized discriminant function coefficients (i.e. coefficients with large absolute values correspond to variables with greater discriminating ability). The discriminant functions (structure matrices) were used to identify the motivation constructs that could be removed from the model (loading < 0.3 ). Three post hoc analyses using the stepwise method were also utilized to nominate motivation constructs for removal. Lastly, the classification with the "leave-one-out classification" for cross-validation method was used for verification.

The motivation scale items derived from the literature (except Entrepreneurship) were adapted and modified in the SPD context for this study (Table 2). The reflective measurement items for the three types of continuous intention including continuous intention to ideate, collaborate, and socialize, were adapted from previous studies on continuous behavioral intention in virtual collaborative communities $[9,13$, 66]. A seven-point Likert-type scale (where $1=$ strongly disagree and $7=$ strongly agree) was used for measuring co-innovation motivations as well as for the intention construct. However, the data was later discretized into two groups. We used supervised discretization (average as the cutting point), which can improve classification performance [32]. In each round, respondents were divided into two groups, high and low continuous intention to ideate, collaborate or socialize (intention constructs were re-coded to dummy variables). High continuous intention refers to above average intention and low continuous intention refers below average intention.

Table 2. Me as urement Items

\begin{tabular}{ll}
\hline CONSTRUCT & DEFINITION \\
\hline Financial Gain [20,39] & $\begin{array}{l}\text { Desire to obtain financial incentives } \\
\text { associated with performance }\end{array}$ \\
\hline Recognition [39] & $\begin{array}{l}\text { Desire to acquire professional status } \\
\text { accorded to qualifications }\end{array}$ \\
\hline Learning [50] & $\begin{array}{l}\text { Desire to acquire skills and knowledge } \\
\text { for personal development }\end{array}$ \\
\hline Self-efficacy [39] & $\begin{array}{l}\text { Desire to prove own ability in reaching } \\
\text { innovation goals }\end{array}$ \\
\hline Entrepreneurship (new) & $\begin{array}{l}\text { Desire to orientate conduct towards } \\
\text { entrepreneurial tasks and outcomes }\end{array}$ \\
\hline Networking [49] & $\begin{array}{l}\text { Desire to expend effort to interact, } \\
\text { socialize and network with other actors }\end{array}$ \\
\hline Enjoyment [20,39] & $\begin{array}{l}\text { Desire to receive the gratification of } \\
\text { action }\end{array}$ \\
\hline Altruism [11, 50, 64] & $\begin{array}{l}\text { Desire to selfless actions that benefit } \\
\text { the welfare of innovation community }\end{array}$ \\
\hline
\end{tabular}




\section{Results}

A sample of 320 Quirky members participated in the online survey asking for their motivations, behavioral intentions, and demographics as well as the three-screening question to determine if they had participated in ideation, collaboration, and socialization activities for at least consecutive six months. More women (59\%) participated in the survey compared to men (41\%). Most the respondents were between 26 and 65 years old (84\%), and over $70 \%$ had at least some college education. Nearly $60 \%$ of the respondents were employed outside of their participation in the network.

\subsection{Dimensionality and Reliability}

We ran an exploratory factor analysis (EFA) to check the dimensionality of the selected motivation constructs. We used Maximum Likelihood with Oblique rotation (direct oblimin) to investigate the relative importance of each item. Oblique rotation was used to preserve the unique variance of each measure, achieve more generalizable results, and render a more optimum solution $[16,53]$. The Kaiser-Meyer-Olkin measure of sampling adequacy was 0.88 , above the minimum value of 0.6 , and Bartlett's test of Sphericity was significant, indicating that correlations between items were sufficiently large for EFA $\left(\chi^{2}=4936, \mathrm{p}<\right.$ $0.00)$. Given these indicators, factor analysis was deemed to be suitable for the eight constructs.

Reliability tests were then conducted on the eight constructs of motivation. The reliability tests were used to identify whether the previous scales were reliable to use in the study. As shown in Table 3, Cronbach's Alpha for each of motivation constructs exceeded the recommended level of 0.70. All items demonstrated good reliability to use for further analysis in the study.

Table 3. Results of re liability test

\begin{tabular}{llll}
\hline \multicolumn{1}{c}{ FACTORS } & $\boldsymbol{\alpha}$ & CR & AVE \\
\hline Altruism & .86 & .91 & .78 \\
\hline Enjoyment & .94 & .96 & .86 \\
\hline Entrepreneurship & .80 & .87 & .62 \\
\hline Learning & .85 & .90 & .69 \\
\hline Networking & .91 & .94 & .79 \\
\hline Self-efficacy & .88 & .92 & .74 \\
\hline Financial Gain & .89 & .92 & .75 \\
\hline Recognition & .91 & .94 & .75 \\
\hline
\end{tabular}

The convergent validity and discriminant validity were tested: all Average Variance Extracted (AVE) were higher than 0.50 [27]. The square root of the AVE of each construct was larger than the correlations of this construct with the other constructs [18], and the inter-construct correlations were all well below the
0.90 threshold [27]. The results suggest adequate convergent and discriminant validity (Tables 4), where the diagonal elements are the square root of the shared variance between the constructs and their measures (AVE).

Table 4. Corre lation matrix

\begin{tabular}{lllllllll}
\hline & $\mathbf{1}$ & $\mathbf{2}$ & $\mathbf{3}$ & $\mathbf{4}$ & $\mathbf{5}$ & $\mathbf{6}$ & $\mathbf{7}$ & $\mathbf{8}$ \\
\hline 1 Altruism & $\mathbf{. 8 8}$ & & & & & & & \\
\hline 2 Enjoyment & .58 & $\mathbf{. 9 3}$ & & & & & & \\
\hline 3 Entrepreneurship & .35 & .53 & $\mathbf{. 7 9}$ & & & & & \\
\hline 4 Learning & .42 & .43 & .57 & $\mathbf{. 8 3}$ & & & & \\
\hline 5 Networking & .57 & .45 & .16 & .33 & $\mathbf{. 8 9}$ & & & \\
\hline 6 Self-efficacy & .39 & .24 & .38 & .47 & .39 & $\mathbf{. 8 6}$ & & \\
\hline 7 Financial Gain & .19 & .27 & .3 & .22 & .23 & .18 & $\mathbf{. 8 7}$ & \\
\hline 8 Recognition & .33 & .22 & .33 & .49 & .50 & .53 & .42 & $\mathbf{. 8 9}$ \\
\hline
\end{tabular}

\subsection{Discriminant Function Analysis}

A multiple discriminant analysis was conducted to distinguish different actor groups based on their level of willingness to participate in co-innovation activities. This process helped assess the relative importance of co-innovation motivations and their ability to predict actor co-innovation behavioral intention. The Tests of Equality of Group Means show that the groups differ significantly on every motivation constructs for continuous intention to ideate (Wilks' $\Lambda: 0.83-0.95, \mathrm{p}<0.00$ ), collaborate (Wilks' $\Lambda$ : 0.84 $-0.97, \mathrm{p}<0.01$ ), and socialize (Wilks' $\Lambda$ : $0.74-0.99$, $\mathrm{p}<0.00$; except for financial motivations). The Test of Homogeneity of Variances was significant; however, the discriminant function analyses could still be robust due to the lack of outliers, sample size, and relatively equal log determinants [61].

The Eigenvalue on discriminant functions (the quantity maximized by the discriminant function coefficients obtained) was 0.410 for ideation, 0.504 for collaboration, and 0.617 for socialization, indicating the proportion of variance explained. The large Eigenvalues were associated with strong functions. The canonical correlations on the discriminant functions were 0.54 for ideation, 0.58 for collaboration, and 0.62 for socialization, explaining $30 \%, 34 \%$, and $38 \%$ of variances in the dependent variables, respectively.

The results of the discriminant analysis (see Tables 5-7) indicate that the discriminant function was significant for ideation (Wilks' $\Lambda: 0.71$ at $\mathrm{p}<0.00$ and $\chi^{2}(8)$ : 90.30), collaboration (Wilks' $\Lambda: 0.66$ at $p<0.00$ and $\chi^{2}(8): 107.56$ ), and socialization (Wilks' $\Lambda$ : 0.62 at $\mathrm{p}<0.00$ and $\left.\chi^{2}(8): 126.47\right)$.

The standardized coefficients reflect the contribution of one motivation construct in the context of the other motivation constructs in the model. Since we tested for redundancy and multicollinearity, the low standardized coefficients mean that the groups do 
not differ much on the motivation constructs with low coefficients.

For ideation (Table 5), the canonical discriminant function coefficients and the discriminant function loadings suggest that Learning, Financial Gain, and Entrepreneurship were the most important motivations for discriminating between ideators and non-ideators. Since loadings are more valid than canonical coefficients in prediction, the relative importance of the motivations in driving ideation was in this order: Learning, Financial Gain, Entrepreneurship, Recognition, Enjoyment, Self-efficacy, Altruism, and Networking. Post hoc analysis using the stepwise method suggested that the ideators are members highly motivated with Learning, Financial Gain and Entrepreneurship opportunities.

Table 5. Discriminant analys is re sults for ideation

\begin{tabular}{lcc}
\hline FACTORS & $\begin{array}{c}\text { CANONICAL } \\
\text { COEFFICIENT }\end{array}$ & $\begin{array}{c}\text { DISCRIMINANT } \\
\text { LOADING }\end{array}$ \\
\hline Learning & $\mathbf{. 3 4 5}$ & $\mathbf{. 7 0 1}$ \\
\hline Financial Gain & $\mathbf{. 5 2 4}$ & $\mathbf{. 6 8 6}$ \\
\hline Entrepreneurship & $\mathbf{. 3 0 1}$ & $\mathbf{. 6 7 7}$ \\
\hline Recognition & .160 & .541 \\
\hline Enjoyment & .052 & .480 \\
\hline Self-efficacy & .136 & .470 \\
\hline Altruism & .079 & .450 \\
\hline Networking & -.045 & .358 \\
\hline standardized & &
\end{tabular}

For collaboration behavior (Table 6), the canonical discriminant function coefficients and the discriminant function loadings followed by stepwise post hoc analysis indicate that Learning and Enjoyment are most important for discriminating between collaborators and non-collaborators. According to the loadings, the relative importance of the motivations in driving collaboration was in this order: Learning, Enjoyment, Entrepreneurship, Altruism, Financial Gain, and Self-efficacy. Networking and Recognition had loadings less than the cut-off value of 0.30 [25]. Thus, those motivations were considered less important variables, meaning that they were less successful as predictors of continuous intention to collaboration.

Table 6. Dis criminant analys is results for collaboration

\begin{tabular}{lcc}
\hline FACTORS & $\begin{array}{c}\text { CANONICAL } \\
\text { COEFFICIENT }\end{array}$ & $\begin{array}{c}\text { DISCRIMINANT } \\
\text { LOADING }\end{array}$ \\
\hline Learning & $\mathbf{. 8 0 4}$ & $\mathbf{. 8 8 7}$ \\
\hline Enjoyment & $\mathbf{. 2 7 3}$ & $\mathbf{. 6 0 7}$ \\
\hline Entrepreneurship & .023 & .582 \\
\hline Altruism & .224 & .545 \\
\hline Financial Gain & .197 & .338 \\
\hline Self-efficacy & -.010 & .301 \\
\hline Networking & -.126 & .267 \\
\hline Recognition & -.193 & .229 \\
\hline * standardized & &
\end{tabular}

For socialization behavior (Table 7), the canonical discriminant function coefficients and post hoc analysis indicate that Altruism, Networking, and Enjoyment are most important for discriminating between actors willing to socialize and those with low intention to socialize. Recognition, Entrepreneurship, and Financial Gain had loadings less than the cut-off value of 0.30 and were considered less important variables, meaning that they were less successful as predictors of continuous intention to socialize.

Table 7. Discriminant analys is results for socialization

\begin{tabular}{lcc}
\hline FACTORS & $\begin{array}{c}\text { CANONICAL } \\
\text { COEFFICIENT }\end{array}$ & $\begin{array}{c}\text { DISCRIMINANT } \\
\text { LOADING }\end{array}$ \\
\hline Altruism & $\mathbf{. 3 5 1}$ & $\mathbf{. 7 4 7}$ \\
\hline Networking & $\mathbf{. 5 0 1}$ & $\mathbf{. 7 0 8}$ \\
\hline Enjoyment & $\mathbf{. 4 7 9}$ & $\mathbf{. 6 7 8}$ \\
\hline Learning & .126 & .421 \\
\hline Self-efficacy & .227 & .402 \\
\hline Recognition & -.093 & .286 \\
\hline Entrepreneurship & -.139 & .271 \\
\hline Financial Gain & -.271 & .084 \\
\hline * standardized & &
\end{tabular}

\subsection{Classification and Actor Profiling}

The classification tables were used to assess how well the discriminant function profile actors for each group of intention constructs. The first group of actors, highly motivated to ideate, are classified as Ideators. The discriminant function for Ideators correctly classified $87 \%$ of cases with the high intention to ideate (sensitivity) and $63 \%$ of cases with the low intention (specificity). The classification results were satisfactory as $76 \%$ and $74 \%$ of original grouped cases and of cross-validated grouped cases were correctly classified respectively (Table 8).

Table 8. Classification results for ideation

\begin{tabular}{lrrr}
\hline \multirow{2}{*}{ Original } & & LOW & HIGH \\
\hline \multirow{2}{*}{ Cross-validated } & LOW & $\mathbf{6 3 . 4 \%}$ & $36.6 \%$ \\
\cline { 2 - 4 } & HIGH & $13.0 \%$ & $\mathbf{8 7 . 0 \%}$ \\
\cline { 2 - 4 } & LOW & $\mathbf{6 2 . 6 \%}$ & $37.4 \%$ \\
\hline
\end{tabular}

The second group of actors, mainly interested in collaboration, are classified as Collaborators. Collaborators are actors who pursue SPD as a fun social learning experience. The discriminant function for collaborators correctly classified $85 \%$ of cases with high intention and $69 \%$ of cases with low intention. The classification results were satisfactory as $78 \%$ and $75 \%$ of originally grouped cases and of cross-validated grouped cases were correctly classified respectively (Table 9). 
Table 9. Classification results for collaboration

\begin{tabular}{lrrr}
\hline & & LOW & HIGH \\
\hline \multirow{2}{*}{ Original } & LOW & $\mathbf{6 9 . 2 \%}$ & $30.8 \%$ \\
\cline { 2 - 4 } & HIGH & $15.4 \%$ & $\mathbf{8 4 . 6 \%}$ \\
\hline \multirow{2}{*}{ Cross-validated } & LOW & $\mathbf{6 4 . 2 \%}$ & $35.8 \%$ \\
\cline { 2 - 4 } & HIGH & $16.1 \%$ & $\mathbf{8 3 . 9 \%}$ \\
\hline
\end{tabular}

The third group of actors is classified as Networkers, who join SPD networks mainly to socialize with other actors, have fun, and help others. Therefore, they are more engaged in communication, networking, and socialization behaviors rather than with the direct contributions to new product development processes. The discriminant function for Networkers correctly classified $82 \%$ of cases with high intention to socialize and $77 \%$ of cases with low intention. The classification results were satisfactory, as $80 \%$ of the original grouped cases and $79 \%$ of the cross-validated grouped cases were correctly classified (Table 10).

Table 10. Classification results for socialization

\begin{tabular}{lrrr}
\hline \multirow{2}{*}{ Original } & & LOW & HIGH \\
\hline \multirow{2}{*}{ Cross-validated } & LOW & $\mathbf{7 7 . 5 \%}$ & $22.5 \%$ \\
\cline { 2 - 4 } & HIGH & $18.3 \%$ & $\mathbf{8 1 . 7 \%}$ \\
\cline { 2 - 4 } & LOW & $\mathbf{7 7 . 5 \%}$ & $22.5 \%$ \\
\hline
\end{tabular}

\section{Discussion}

This study applies existing open innovation motivation constructs to SPD networks and contributes the development of a multi-dimensional SPD motivation scale consisting of Altruism, Enjoyment, Entrepreneurship, Learning, Networking, Self-efficacy, Financial Gain, and Recognition. After validating the motivation constructs (or dimensions), we show that these constructs are significant determinants in explaining why actors contribute to SPD networks. We defined three discriminant functions to identify three groups of actors with the high intention to Ideate, Collaborate, and Socialize. Using these relationships, we developed three classification models.

The findings (Figure 1) reveal profiles of SPD members who have higher than the average intention to ideate, collaborate, and socialize. These categories include (1) Ideators motivated by extrinsic motivations, mainly Financial Gain, Learning, and Entrepreneurship; (2) Collaborators motivated by a mix of intrinsic and extrinsic motivations, mainly Learning and Enjoyment; and (3) Networkers who are motivated by intrinsic motivations, mainly Altruism, Networking and Enjoyment. While all motivations affect the continuous intention to ideate, the findings show that Self-efficacy, Networking, and Recognition do not discriminate collaborators from non- collaborators. On the other hand, Recognition, Entrepreneurship, and Financial Gain do not separate Networkers from non-networkers.

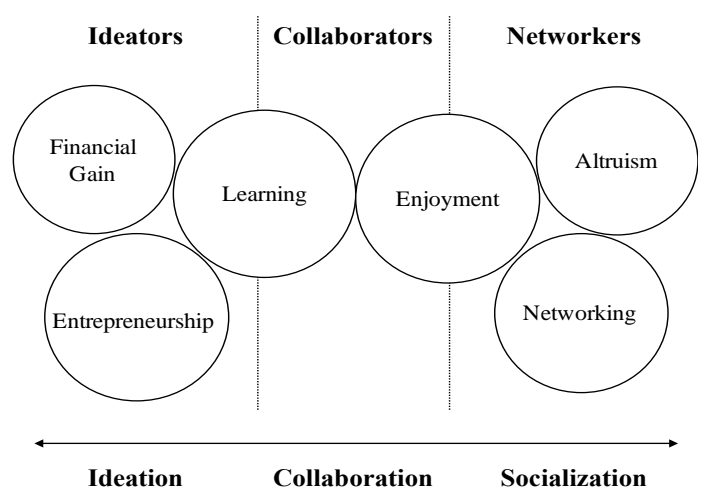

Figure 1. Summary of findings

In terms of motivation to ideate, actors in SPD networks submit new product ideas, expect feedback from the community and SDP coordinator, and receive financial rewards if their ideas are selected for further development. Ideators can use the platform not only to compete with other actors for rewards but also as a testbed for their own entrepreneurial ideas. SPD networks offer several learning opportunities through feedback from the SPD coordinator and community. These opportunities enable Ideators to gain firsthand innovation knowledge through active learning opportunities and satisfy their entrepreneurial mindset.

Findings suggest that actors continuously participate in collaboration if they find the process both enjoyable and educational. Collaboration can satisfy these motivations because of the cognitive compensation and interpersonal enjoyment [5]. Although collaboration and ideation share Learning motivation, Enjoyment plays a greater role in motivating collaboration, since the ideation process is more intense in terms of workload, risk, and competition. While Ideators compete in submitting new product ideas for their own financial or entrepreneurial gains, Collaborators can freely collaborate on different SPD projects based on their personal preferences and interests.

Networkers, the third group of actors, may limit their contribution to networking and helping other actors without directly or formally participating in any projects. These actors contribute to the network by strengthening the social aspect of SPD network. They consider the SPD network as a professional community where they can get in touch with likeminded individuals and help the community to expand their socio-professional network. Additionally, some actors motivated by social aspects of the SPD network are likely to participate in the social activities, which may keep them interested and entertained throughout 
the co-innovation process. Therefore, SPD networks are a different environment from traditional open innovation communities where participation is limited to highly skilled actors.

Finally, the classification models are not mutually exclusive but may be collectively exhaustive due to the nature of the discriminant functions. This means that actors can exhibit a collection of motivations and be interested in more than one SPD activity. For example, an actor who is interested in educational, social, and entertaining aspects of the SPD would contribute to both collaboration and socialization. Thus, all motivations together could lead to participation in all key activities but to different behavioral levels.

\subsection{Theoretical Contribution}

Our findings provide insight into SPD actor behavior and implications for developing more sustainable SPD platforms. The results of this study suggest that both extrinsic and intrinsic motivations are significant in driving SPD participation. While prior studies classified actors mainly as one category of hobbyists $[4,58]$, we identify three different groups of actors in this study. Specifically, actors who are financially and practically motivated are active Ideators because they take advantage of the SPD platform in search of financial gains as well as firsthand innovation learning experience. Collaborators are professional hobbyists utilizing the platform as a learning platform while enjoying exploring the open innovative process. Networkers are more interested in social aspects of the network, so rather than engaging directly in any project, they benefit from SPD network as a professional community. These three groups of actors offer an opportunity for understanding actor behavior. The findings also help with the systematic investigation of SPD reward mechanisms in the relationship to the network business models. The results also provide new insights in demonstrating the relative importance of different motivations in influencing intention to co-innovate.

\subsection{Practical Implications}

SPD networks need to be designed, positioned and governed in consideration of various actor motivations. This study suggests a more personalized reward system based on business goals and requirements may be effective to motivate different types of individual contributors. When actors receive more desirable rewards, they are more likely to participate in the activities that the network is looking for. Platforms designed to accommodate these motivations will gain more popularity among social actors and maintain their participation and contribution.

When an SPD network's goal is to generate concepts for new products, the SPD model could promote ideation by offering more monetary rewards and assisting actors in finding the right learning experience based on their entrepreneurial goals. Ideation motivation could be encouraged when the platform communicates these values and shares best practices and other actors' success stories. Platforms can also provide feedback on actors' new ideas to enhance their learning process.

A new generation of SPD platforms increasingly add collaborative features and encourage teamwork. These networks should not only reward the actors with learning opportunities (e.g. feedback) but also satisfy motivations such as entertainment and pleasure. For example, gamification of collaborative activities may engage more actors. Additionally, co-innovation features that help collaborative actors find the right projects to join might better maintain the participation of actors looking for a specific learning or entertainment opportunities.

Some SPD networks are designed as socioprofessional communities, creating value through social exchange and knowledge sharing. When an SPD business model requires a high rate of socialization (e.g. for social validation of new product), the SPD coordinators could invest in more social networking features and highlight the altruistic features of the network. Networking motivation can be satisfied when the platform offers communication and social interaction independent from project involvement. As a result, more actors would join the network, participate in the conversations, and as a result, may participate in ideation or collaboration in the future.

\section{Conclusions}

This study draws from prior research on coinnovation motivation to develop a multi-dimensional SPD motivation scale consisting of Financial Gain, Recognition, Learning, Altruism, Enjoyment, Selfefficacy Entrepreneurship, and Networking. Three discriminant functions were developed to classify actors into three groups: Ideators, Collaborators, and Networkers. The proposed classification model can help SPD coordinators examine and refine their reward system to engage social actors to continuously contribute to co-innovation behaviors.

Because these classifications are based on data from one SPD network, additional research is necessary to cross-validate previous findings in different SPD networks. Extensions of our classification approach to different co-innovation 
models will provide additional insights on these innovation phenomena. Future research to categorize SPD platform features in relation to co-innovation motivations will contribute to SPD platform designs to meet individual actors' preferences and goals. A deeper understanding of SPD actors' personality differences would be beneficial in expanding the constructs for practical application. Longitudinal studies focusing on SPD network sustainability would further our understanding of how co-innovation motivations evolve over time. Finally, future research can examine our classification models in relation to SPD outcomes, such as actors' actual contribution, success of new products or quality and quantity of contributions.

\section{References}

[1] Abhari, K., Davidson, E.J., and Xiao, B. Taking Open Innovation to the Next Level: A Conceptual Model of Social Product Development (SPD). AMCIS 2016 Proceedings, (2016).

[2] Abhari, K., Davidson, E.J., and Xiao, B. Co-Innovation Platform Affordances: Developing a Conceptual Model and Measurement Instrument. Industrial Management \& Data Systems 117, 5 (2017), 873-895.

[3] Antikainen, M.J., Mäkipää, M., and Ahonen, M. Motivating and supporting collaboration in open innovation. European Journal of Innovation Management 13, 1 (2010), 100-119.

[4] Antikainen, M.J. and Vaataja, H.K. Rewarding in open innovation communities--how to motivate members. International Journal of Entrepreneurship and Innovation Management 11, 4 (2010), 440-456

[5] Balijepally, V., Mahapatra, R., Nerur, S.P., and Nerur, S. Assessing Personality Profiles of Software Developers in Agile Development Teams. Communications of the Association for Information Systems 18, 18 (2006), 55-75.

[6] Battistella, C. and Nonino, F. What drives collective innovation? Exploring the system of drivers for motivations in open innovation, Web-based platforms. Information Research 17, 1 (2012), 1-33.

[7] Battistella, C. and Nonino, F. Exploring the impact of motivations on the attraction of innovation roles in open innovation web-based platforms. Production Planning \& Control 24, 2-3 (2013), 226-245.

[8] Bechmann, A. and Lomborg, S. Mapping actor roles in social media: Different perspectives on value creation in theories of user participation. New Media \& Society 15, 5 (2012), 765-781.

[9] Bhattacherjee, A. and Premkumar, G. Understanding Information Systems Continuance: an Expectation-Confirmation Model. MIS Quarterly 25, 3 (2001), 351-370.

[10] Boudreau, K. and Lakhani, K. How to Manage Outside Innovation. MIT Sloan Management Review 50, 4 (2009), 69-76.

[11] Bretschneider, U., Rajagopalan, B., and Leimeister, J.M. Idea Generation in Virtual Communities for Innovation: The Influence of Participants' Motivation on Idea Quality. 45th Annual Hawaii International Conference on System Sciences (HICSS), IEEE (2012), 3467-3479.

[12] Brown, B.T. and Wyatt, J. Design Thinking for Social Innovation. Stanford Social Innovation Review 12, 1 (2010), 30-
35.

[13] Chen, I.Y.L. The factors influencing members' continuance intentions in professional virtual communities a longitudinal study. Journal of Information Science 33, 4 (2007), 451-467.

[14] Chen, L., Marsden, J.R., and Zhang, Z. Theory and Analysis of Company-Sponsored Value Co-Creation. Journal of Management Information Systems 29, 2 (2012), 141-172.

[15] Constantinides, E., Wittenberg, K.A., and Lorenzo-Romero, C. Co-Innovation: motivators and inhibitors for customers to participate in online co-creation processes. The 13th International Marketing Trends Conference, (2014), 1-11.

[16] Costello, A.B. and Osborne, J.W. Best Practices in Exploratory Factor Analysis. Practical Assessment, Research \& Evaluation 10, 7 (2005), 1-9.

[17] Cullen, J. Information work and the opportunity of innovation: From corporate to social product development. Business Information Review 24, 3 (2007), 156-160.

[18] Fornell, C. and Larcker, D.F. Structural Equation Models with Unobservable Variables and Measurement Error: Algebra and Statistics. Journal of Marketing Research 18, (1981), 382-388.

[19] Franke, N. and Schreier, M. Entrepreneurial opportunities with toolkits for user innovation and design. International Journal on Media Management 4, 4 (2002), 225-234.

[20] Frey, K., Lüthje, C., and Haag, S. Whom Should Firms Attract to Open Innovation Platforms? The Role of Knowledge Diversity and Motivation. Long Range Planning 44, 5-6 (2011), 397-420.

[21] Füller, J. Why consumers engage in virtual new product developments initiated by producers. Advances in Consumer Research 33, 1 (2006), 639-646.

[22] Füller, J. Refining Virtual Co-Creation from a Consumer Perspective. California Management Review 52, 2 (2010), 98-122.

[23] Füller, J., Hutter, K., Hautz, J., and Matzler, K. User Roles and Contributions in Innovation-Contest Communities. Journal of Management Information Systems 31, 1 (2014), 273-308.

[24] Gloor, P.A. Swarm creativity: competitive advantage through collaborative innovation networks. Oxford University Press, New York, 2006

[25] Hair, J.F. and Anderson, R.E. Multivariate Data Analysis. Prentice Hall Higher Education, Upper Saddle River, 2010.

[26] Hair, J.F., Black, W.C., Babin, B.J., and Anderson, R.E. Multivariate Data Analysis. Pearson Education Limited, Upper Saddle River, 2013.

[27] Hair, J.F., Hult, G.T.M., Ringle, C., and Sarstedt, M. A Primer on Partial Least Squares Structural Equation Modeling (PLSSEM). SAGE Publications, Thousand Oaks, 2013.

[28] Han, K., Oh, W., Im, K.S.K., Chang, R.R.M., Oh, H., and Pinsonneault, A. Value Cocreation and Wealth Spillover in Open Innovation Alliances. MIS Quarterly 36, 1 (2012), 1-26.

[29] Henkel, J., Schöberl, S., and Alexy, O. The emergence of openness: How and why firms adopt selective revealing in open innovation. Research Policy 43, 5 (2014), 879-890.

[30] von Hippel, E. and Von Krogh, G. Open source software and the "private-collective" innovation model: Issues for organization science. Organization science 14, 2 (2003), 209-223.

[31] von Hippel, E., Ogawa, S., and De Jong, J.P.J. The Age of the Consumer-Innovator. MIT Sloan Management Review 53, 1 (2011), 27-35. 
[32] Ho, R. Handbook of Univariate and Multivariate Data Analysis with IBM SPSS, Second Edition. CRC Press, 2013.

[33] Hoyer, W.D., Chandy, R., Dorotic, M., Krafft, M., and Singh, S.S. Consumer Cocreation in New Product Development. Journal of Service Research 13, 3 (2010), 283-296.

[34] Jeppesen, L.B. and Frederiksen, L. Why do users contribute to firm-hosted user communities? The case of computer-controlled music instruments. Organization science 17, 1 (2006), 45-63.

[35] Jeppesen, L.B. and Laursen, K. Lead Users as Facilitators of Knowledge Sharing in a Community Setting. 2007.

[36] Kahnert, D., Menez, R., and Blättel-Mink, B. Coordination and Motivation of Customer Contribution as Social Innovation: The Case of Crytek. In H.W. Franz, J. Hochgerner and J. Howaldt, eds., Challenge Social Innovation: Potentials for Business, Social Entrepreneurship, Welfare and Civil Society. Springer, New York, 2012, 293-306.

[37] Krogh, G. Von, Haefliger, S., Speath, S., and Wallin, M.W. Carrots and rainbows: Motivation and social practice in open source software development. MIS Quarterly 36, 2 (2012), 649676.

[38] Lakhani, K. and Wolf, R. Why Hackers Do What They Do: Understanding Motivation and Effort in Free / Open Source Software Projects. Perspectives on free and open source software 1, (2005), 3-22.

[39] Li, Y., Tan, C.-H.H., and Teo, H.-H.H. Leadership characteristics and developers' motivation in open source software development. Information \& Management 49, 5 (2012), 257-267.

[40] Littler, D., Leverick, F., and Bruce, M. Factors Affecting the Process of Collaborative Development: A Study of UK

Manufacturers and Communications Technology Products. Journal of Product Innovation Management 12, 1 (1995), 16-32.

[41] Martini, A. The role of social software for customer cocreation: does it change the practice for innovation. International Journal of Engineering Business Management 4, (2012).

[42] Martini, A., Massa, S., and Testa, S. The Role of Social Software for Customer Co-Creation : Does It Change the Practice for Innovation? Regular Paper. International Journal of Engineering Business Management 4, 1 (2012), 1-10.

[43] Mesgari, M. and Faraj, S. Technology Affordances: The Case of wikipedia. 18th Americas Conference on Information Systems (AMCIS 2012), (2012), 3833-3841.

[44] Nambisan, S. Designing Virtual Customer Environments for New Product Development: Toward a Theory. Academy of Management Review 27, 3 (2002), 392-413.

[45] Nambisan, S. Information Systems as a Reference Discipline for New Product Development. MIS Quarterly 27, 1 (2003), 1-18.

[46] Nambisan, S. Virtual Customer Environments: IT-Enabled Customer Co-innovation and Value Co-creation. In S. Nambisan, ed., Information Technology and Product Development. Springer US, 2009, 109-127.

[47] Nambisan, S. and Baron, R.A. Virtual Customer Environments: Testing a Model of Voluntary Participation in Value Co-creation Activities. Journal of Product Innovation Management 26, 4 (2009), 388-406.

[48] Nov, O. What motivates wikipedians? Communications of the ACM 50, 11 (2007), 60-64.

[49] Oishi, S., Kesebir, S., Miao, F.F., et al. Residential mobility increases motivation to expand social network: But why? Journal of Experimental Social Psychology 49, 2 (2013), 217-223.
[50] Oreg, S. and Nov, O. Exploring motivations for contributing to open source initiatives: The roles of contribution context and personal values. Computers in Human Behavior 24, 5 (2008), 2055-2073.

[51] Paulini, M., Murty, P., and Maher, M.L.M. Design Processes in Collective Innovation Communities: a Study of Communication. CoDesign 9, 2 (2013), 90-112.

[52] Peterson, A. and Schaefer, D. Social Product Development: Introduction, Overview, and Current Status. In D. Schaefer, ed., Product Development in the Socio-sphere. Springer, Cham, 2014, $1-33$.

[53] Petter, S., Straub, D., and Rai, A. Specifying Formative Constructs in Information Systems Research. MIS Quarterly 31, 4 (2007), 623-656.

[54] Piller, F., Vossen, A., and Ihl, C. From Social Media to Social Product Development: The Impact of Social Media on Co-Creation of Innovation. Die Unternehmung 65, 1 (2012), 7-27.

[55] Ridings, C.M. and Gefen, D. Virtual community attraction: Why people hang out online. Journal of Computer-Mediated Communication 10, 1 (2004).

[56] Romero, D., Molina, A., and Camarinha-Matos, L.M. Coinnovation and collaborative networks. Production Planning \& Control 22, 5-6 (2011), 445-446.

[57] Seltzer, E. and Mahmoudi, D. Citizen Participation, Open Innovation, and Crowdsourcing: Challenges and Opportunities for Planning. Journal of Planning Literature 28, 1 (2012), 3-18.

[58] Shah, S.K. Motivation, Forms and the Viability of Hybrid Governance in Open Source Software Development. Management Science 52, 7 (2013), 1000-1014.

[59] Sorensen, E. and Torfing, J. Enhancing Collaborative Innovation in the Public Sector. Administration \& Society 43, 8 (2011), 842-868.

[60] Sutcliffe, a. G., Gonzalez, V., Binder, J., and Nevarez, G. Social Mediating Technologies: Social Affordances and Functionalities. International Journal of Human-Computer Interaction 27, 11 (2011), 1037-1065.

[61] Tabachnick, B.G. and Fidell, L.S. Using multivariate statistics. Pearson Education, Boston, 2013.

[62] Wasko, M.M. and Faraj, S. Why Should I Share? Examining Social Capital and Knowledge Contribution in Electronic Network of Practice. MIS Quarterly 29, 1 (2005), 35-57.

[63] Wiertz, C. and de Ruyter, K. Beyond the Call of Duty: Why Customers Contribute to Firm-hosted Commercial Online Communities. Organization Studies 28, 3 (2007), 347-376.

[64] Wu, C.-G., Gerlach, J.H., and Young, C.E. An empirical analysis of open source software developers' motivations and continuance intentions. Information \& Management 44, 3 (2007), 253-262.

[65] Wu, D., Rosen, D.W., Panchal, J.H., and Schaefer, D. Understanding Communication and Collaboration in Social Product Development Through Social Network Analysis. Journal of Computing and Information Science in Engineering 16, 1 (2015), 1-10.

[66] Zhang, Y., Fang, Y., Wei, K.-K., and Chen, H. Exploring the role of psychological safety in promoting the intention to continue sharing knowledge in virtual communities. International Journal of Information Management 30, 5 (2010), 425-436. 